\title{
Aragonés y catalán en un libro de cuentas turolense del siglo XV
}

\author{
Javier Giralt Latorre ${ }^{1}$
}

Recibido: 14 de diciembre de 2015 / Aceptado: 3 de diciembre de 2017

Resumen. Hasta el siglo Xv, el aragonés y el catalán fueron lenguas de uso habitual en la Corona de Aragón, tanto en los escritos reales como en los notariales. A partir de entonces, se acentuó el empleo del castellano en la administración aragonesa, aunque en los documentos de la época se plasmó la resistencia de las lenguas autóctonas de Aragón a ser substituidas por el romance sobrevenido. Una buena muestra de ello es el libro de cuentas del concejo de Mirambel (Teruel), redactado entre 1472 y 1489, del cual ofrecemos en estas páginas un análisis lingüístico para demostrar la convivencia de lenguas existente todavía a finales del siglo Xv.

Palabras clave: Aragonés; Catalán; Historia de la lengua; Dialectología; Variación; Contacto de lenguas; Edad Media; Teruel.

\section{[en] Aragonese and Catalan in a 15th-century Teruel ledger}

Summary. Up to the 15th century, Aragonese and Catalan were commonly used languages in both royal and notarial documents in the Crown of Aragon. From then on, the use of Castilian by the Aragonese administration increased, although the resistance of the native Aragonese languages to their Castilian substitution is reflected in documents from the time. A good example of that can be seen in the 1472-1489 ledger of the Council of Mirambel (Teruel). In this study, we undertake a linguistic analysis on the ledger to demonstrate the coexistence of the languages that were still in use at the end of the 15 th century.

Key words: Aragonese; Catalan; History of language; Dialectology; Variation; Contact of languages; Middle Ages; Teruel.

Sumario. 1. Introducción. 2. Tradiciones grafémicas aragonesas. 3. Rasgos fonéticos. 4. Rasgos gramaticales. 5. Numerales. 6. Léxico- 7. Anotaciones escritas en catalán. 8. Consideraciones finales. 9. Bibliografía

Cómo citar: Giralt Latorre, J. (2018). Aragonés y catalán en un libro de cuentas turolense del siglo xv, en Revista de Filología Románica 35, 9-32.

1 Departamento de Lingüística General e Hispánica. Universidad de Zaragoza jgiralt@unizar.es 


\section{Introducción}

Hasta el siglo Xv, el aragonés y el catalán fueron lenguas de uso habitual en la Corona de Aragón, tanto en los escritos reales como en las notarías y en los concejos. Si bien es cierto que la impronta del castellano en Aragón se inició seguramente ya en el siglo XII y se fue afianzando a lo largo de las dos centurias siguientes, según los testimonios escritos no literarios conocidos, sobre todo de las provincias de Zaragoza y Teruel (Enguita/Arnal 1995: 151), también lo es que las lenguas autóctonas continuaron estando presentes en la redacción de los documentos notariales, más vinculados a la vida cotidiana. Sin embargo, no cabe duda de que a lo largo del siglo XV se acentúa el proceso castellanizador que desembocará en la sustitución lingüística del romance aragonés: primero, con la entronización de Fernando de Castilla, de la dinastía de los Trastámara, en 1412, tras los acuerdos tomados en el Compromiso de Caspe; y, segundo, con la unión dinástica de los reinos de Castilla y Aragón tras el matrimonio de Isabel y Fernando en 1469, y la culminación de la integración de ambas coronas en 1479. A partir de entonces, el empleo del castellano en la administración aragonesa fue imparable, aunque el proceso castellanizador se desarrollara de manera pausada en los siglos posteriores (Enguita/Arnal 1995: 161).

Esta situación se ve reflejada en los documentos de la época, ya que en ellos ha quedado plasmada la débil resistencia del aragonés y, según su procedencia, todavía la influencia del catalán. Esta realidad es justamente la que se observa en un libro de cuentas redactado entre 1472 y 1489 del concejo de Mirambel, localidad ubicada en el extremo sureste de la provincia de Teruel, en la comarca del Maestrazgo. Se trata de un conjunto de cuadernos redactados por los notarios Francisco Montañés y Bernat Cristóbal, a partir de los borradores de ingresos y gastos presentados cada año por los jurados cajoneros o bolseros. Dicho manuscrito, editado por Germán Navarro Espinach (2008), ${ }^{2}$ nos acerca al mundo de las comunidades rurales medievales por ser Mirambel una villa de señorío de pequeñas dimensiones, aspecto este de gran interés para recuperar la historia social del campesinado aragonés. Como señala Navarro Espinach (2008: 14-15), este libro nos abre las puertas de Mirambel y, a través de sus cuentas, tenemos la oportunidad de conocer cómo mandaban sus prohombres y de qué manera utilizaban los gastos y los ingresos de la comunidad para afianzar su poder sobre ella o para reafirmarse frente a los otros pueblos de la bailía. Pero, es mucho más lo que nos aporta este libro contable, puesto que nos ofrece información detallada sobre muchos otros aspectos relativos a la cotidianeidad de los habitantes de Mirambel en el último cuarto del siglo xv: las fiestas anuales del pueblo y los que en ellas intervenían con un especial protagonismo; las romerías y procesiones concelebradas con localidades vecinas a ambos lados de la frontera entre Teruel y Castellón; espacios físicos de la localidad; toponimia del término; la alimentación, sobre todo en las cenas de los oficiales y contadores del concejo; y, por supuesto, el nombre y apellidos de cuantos personajes se van mencionando a lo largo de los 119 folios de que consta el manuscrito.

Asimismo, como ya apunta Navarro Espinach (2008: 23), se trata de un texto que presenta un gran valor desde una perspectiva lingüística, porque en él se hace patente la convivencia de lenguas que se produjo en Aragón en este último tramo de la Edad

El documento original puede consultarse en la base de datos DARA Medieval del Gobierno de Aragón (http:// dara.aragon.es/). 
Media. En este libro de cuentas, sobre una scripta ya claramente castellana, perviven componentes propios del aragonés, de manera que, en ocasiones, coexisten diversas soluciones para un mismo elemento fonético, morfológico o léxico; y, a su vez, se deslizan otros característicos del catalán como consecuencia de la situación fronteriza de Mirambel con las tierras catalanohablantes del Maestrat histórico, al norte de la provincia de Castellón, circunstancia que favoreció un intenso contacto lingüístico que se pone de manifiesto en los apuntes y los albaranes de los bolseros, los cuales fueron copiados y reproducidos por los dos notarios citados. Y, no solamente rasgos catalanes aislados, sino también un total de 130 asientos contables redactados íntegramente en catalán, en los que se insertan de igual modo componentes lingüísticos aragoneses y castellanos.

Es evidente, pues, el interés filológico que nos ofrece este libro de cuentas del concejo de Mirambel de finales del siglo $\mathrm{xV},{ }^{3} \mathrm{y}$ por ello nos proponemos presentar en estas páginas un análisis de la convivencia de lenguas que en él aflora; prestaremos especial atención a los rasgos lingüísticos aragoneses y catalanes que se conservan en los textos escritos en castellano, si bien dedicaremos igualmente un apartado al comentario lingüístico de las anotaciones que aparecen redactadas en catalán. ${ }^{4}$

\section{Tradiciones grafémicas aragonesas ${ }^{5}$}

2.1. En el manuscrito de Mirambel predomina claramente el dígrafo - $n y$ - para representar el fonema /n/: ${ }^{6}$ Alcanyís 1461, Alcanyiç 1579, 2079, acompanyar 280, Benanyell 799, 939, 1181, Ivanyes 193, 454, Yvanyes 314, 369, 818, 989, 1240, 2042, lenya 95, 304, 361, Montanyana 86, Montanyés 1, 18, 25, 26, 27, 79, senyor 5, 8, 36, 40, 41, 42, anyada 9, 204, 483, 1430, anyo 18, 19, 70, 292, 296, Canyada 76, 177, companyero 83,112 , penyorar 1287 , etc. Con escasos testimonios se presentan otras variantes: -ni-, de imitación latina y frecuente en época primitiva, en calonias 1415, 1917, companiero 186, 1334, penioras 1320; -nn- en lennas 346; -n- en algún topónimo y antropónimo, como Alcaniç 281, Alcaniz 561, 673, 718, 799, 1316, 1327, Alcanyç 37, 2029, 2032, 2051, 2090, Benanell 1298, Caniçar 340, Ivanes 2, 8, 89, 134.

2.2. Siguen siendo numerosos los casos de $q u$ con valor de $/ \mathrm{k} /$ ante las vocales /a/ y /o/: merquader 1259, marquas 1259, carasqual 969, carasqua 2187 , vaqua 267 , cinquo 128, 155, 157, 176, 180, 266, blanquo 197, 268, 270, saquar 155, toquasen 216, quando 38, 49, 52, 56, 95, 253, Mayquas 101, Merquador 87, quales 8, 9, 27 , 53, 250, 287, 302, qualesquiere 2203, Francisquo 8, 18, 25, 26, 27, 80, quatorze $303,385,1013,1681$, toquó $10,49,53,68$, frasquas 11 , vaquaron 32 , quántaros 43 ,

Estando ya nuestro texto en imprenta, ha sido publicado un trabajo relativo a un manuscrito del siglo XV de la bailía de Cantavieja (Teruel), localidad vecina de Mirambel, en el que, tras analizar la pervivencia de rasgos aragoneses en la scripta y la confluencia de elementos catalanes, se obtienen resultados muy próximos a los hallados en el libro de cuentas objeto de nuestro estudio (vid. Enguita 2017).

4 Este trabajo se inserta en el proyecto de investigación Aragonés y catalán en el pasado. Diacronía y variación lingüística en documentación de los siglos XIV y XV ubicada en archivos aragoneses, concedido por el Ministerio de Economía y Competitividad (FFI2014-52360-P).

5 Todos los rasgos que se comentan en este apartado también se registran en el catalán antiguo.

6 Los ejemplos citados van acompañados de una numeración que remite a los asientos contables en los que han sido hallados, según la edición de Navarro Espinach (2008). Cuando las ocurrencias son muy numerosas, se indican solamente algunas de ellas. 
284, quantidat 628, 1238, 1925, qual 43, 112, 296, squot 59, acerqua 66, cerquar $683,684,690,799$, cerquaron 705, 796, prediquó 78, toquaron $115,116,146$, quafices 1436, quafiç 1925, etc. La grafía $q$ aparece con dicho valor fonemático en muy pocas ocasiones: quartos $67,1440,1534,1673,1787,1923$, quarteros 1216 , quaresma 78, 244, 245, 257, quarenta 250, quarta 268, quatro 9, 266, 279, 284, quartales 39 , qüestión 95, y en las voces catalanas quarts 553, quart 2160. Por otra parte, el uso de gu con valor de /g/ ante /a/ solamente se anota en fanegua 569, faneguas 615, Bragua 1514.

2.3. En la scripta aragonesa medieval es frecuente la conservación de $-t$ final como consecuencia de la apócope vocálica: libertat 175, necessidat 170, 172, 251, universidat 191, 195, 202, 212, 258, 389, seguredat 2174, propiedat 2174 , ermandat 755, 2067, eredat 1844, 1848, 1849, virtut 1706, caridat 272, 361, 362, 909, 911, 931 , voluntat $1523,1657,1876$, utilidat 205, novidat 1326, paret 1886,2176 , piet $227,271,278,756,976,1500$, pyet 1687 .

2.4. Ha de mencionarse también el uso de $h$ expletiva o inorgánica, de carácter antietimológico, aunque solamente en los numerales hun 24, 394, 618, 1572, 1623, 1920, huna 1778, hochocientos 1300, 1733, huytanta 199, 1438, 1439, 2123, 2168, y los topónimos Huldecuna 290, La Humbría 693, 2143, La Hombría 1668, muy pocos ejemplos que son signo inequívoco de su desuso. También cabe citar el empleo esporádico de $g$ ante $o, u$, con valor palatal: agust 1326, 1328, 1331, 1388, sobregunteros 1360, 1379, gutlars 1330, mogons 1768, agos 740, 1016, viego 2010, viegos 937, 956. Asimismo, se usa el dígrafo -tg- de clara raigambre catalana: ${ }^{7}$ guardiatge 1227,1228 , guardatge 1271, herbatges 167, 181, 222, 236, 248, 290, erbatges 1502 , 2181 , jutge 943, mandatge 1929, misatgero 1870 , misatgeros 171,1526 , peatge 358 , viatge 329, ymatges 1886.

\section{Rasgos fonéticos}

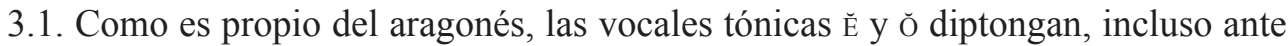
determinados tipos de yod, aunque en el texto de Mirambel solamente se atestigua conviengo 943 como ejemplo de ello. En cambio, aparece el diptongo ante la geminada lateral del sufijo latino -ĚLLU/A: barciellas 117, scudiellas 914, 2146, Moriella 9, 50, 715, 726, 754, 755, Portiell 756, 1962, Colladiello 545, Todoliella 1892, Tudoliella 2058, Camariellas 569. Seguramente proceden del catalán los casos sin diptongación: contan 332, conta 369, 1681, Mosquerolla 804, 806, 925, 929 (cf. Mosqueruela 114), Cantavella 498, 1158 (cf. Cantaviella 1, 8, 17, 36, 56, 61).

3.2. Existe apócope extrema de - e tras la consonante dental/t/, especialmente en el grupo $-n t-:^{8}$ siet $168,173,174,256,490$, dizesiet 396, 1252, restant 733, últimament 942, lugartenient 1939, 2098, contingent 53, 68, 335, 381, 1708, 1778, present 19, 71, 121, 129, primerament 28, 121, purament 128, 129, 467, 496, 611, 612, nuevament 138, largament 298, 2116, extensament 943, delant 1432, 2118, fuent

Resulta difícil determinar la articulación real del dígrafo, si bien cabe suponer que a finales del siglo XV, en Aragón, se correspondería con ya con [t]] (vid. Alvar 2000: 166).

8 Aunque suele aducirse como general este rasgo en aragonés, debería matizarse tal afirmación por cuanto, según demuestra Vázquez (2011c: 152-153), en la toponimia se hallan casos de conservación en los mismos contextos fónicos: abete, rete, fuande, San Climande, etc. 
1746, 1886, adelant 2099, 2105, 2123, precedient 2103, renunciant 943, mediant 802, toquant 255, vint 8, 79, 48, 261, 387, 389, Sant Vicent 705, huest 80, 151, 185 , $197,209,210$, part 15, 25, 53, 68, 201, 204, contrast 1313, 1613, 1740, ajust 73, 90, 91 , agust 1326, 1328, 1331, 1388, port 40, 44, 659, 2037. Hay que añadir el numeral nиеu 145, 152, 153, 159, 171, $228<$ lat. NŎVE, y las voces catalanas rescat 1413, scot 224, 1596, squot 59, 1483, convit 981 .

3.3. También se registra algun caso de apócope de - $o$, aunque prevalece la tendencia a conservarla (cf. Nagore 2003: 132-137): ${ }^{9}$ aliment 1515, 1637, 1655, 1704, 1730 , taxamient 769, jurament 802, 1021, compartimient 1018, compartiment 733, 1578, 1822, 2095 (compartimiento 733, 1319, 1322), quant 870. Por claro influjo del catalán se pierde la vocal en Portiell 756, 1962, ciert 611, 770, almuerç 805, 831, 833, 860, 970, 1017, allmuerç 1321, moç 2077; en cambio, son términos catalanes compromís $^{10} 1539$, vicari 776, 882, procés 733, any 396, tint 2177.

3.4. Como suele ser frecuente en la scripta aragonesa e incluso en el aragonés contemporáneo, en ciertas palabras hay vacilación en el timbre de las vocales átonas. Abundan los ejemplos de cambio entre /e/-/i/ (vid. Lagüéns 2010: 56): carnecería 149, 415, 432, 706, 711, deziembre 296, mesión 1219, mesiones 1371, messión 757, 839 , messiones 896 , proferió 1535,1536 , recebí 326, 327, 927, 1373, recebido 122 , 201, 202, 620, 631, 772, recebida 395, 803, 945, 1300, 2207, recebio 470, 479, 486, 487, 490, 491, recebir 19, 20, 21, 24, screví 1284, 1366, 1426, 1855, screvir 1768, servió $779,785,1742,1932$, servyó 1389 , venieron 792, 916, veniesse 726,754 , veniessen 570, vesitado 52, vesitador 1529, dicisoria 1327, difinicion 2092, 2093, dizían 242, hinvié 2180, hinviaron 167, imbió 1707 , novidat 1326 , redizir $943 . \mathrm{Me}-$ nos numerosos son los casos entre /o/-/u/: acomuladas 126, 1375, 1566, acomulados $128,395,950,954,1286,1862$, acomular 128, acomullar 1655, cobrir 1759, complido 942, complimiento $165,1238,1932$, corredoría 1231,1272 , podiessen 685 , podieron 1643.

3.5. La conservación de F- inicial es sistemática en todo el manuscrito: desfazerlos 913, fazer 8, 65, 66, 110, fazedor 229, fecho 17, 34, 62, 63, 66, 69, 180, feyta 124, 200, 1365, 1625, 1671, 1854, ferero 1324, 1412, 1697, ferrero 349, 2171, 2173, filastra 282, fillastra 173, filla 1049, 1778, 1908, 2210, fillo 17, 155, 973, 1051, 1054, 1055, filo 1896, forno 1759, 1760, 1778, furto 697, 1702.

3.6. El sonido $[\Lambda]<-\mathrm{LY}-$, $-\mathrm{T}$ 'L- se mantiene en muchas ocasiones: concello 34 , $54,59,125,128,130$, concelo 1657 , conseleros $1299,1308,1377$, consellero 1775 , 1939, 2098, conselleros 112, 121, consello 64, filla 1049, 1778, 1908, 2210, filastra 282, fillastra 173, fillo 17, 155, 973, 1051, 1054, 1055, ligallo 1261, 1380, 1419, 1460, ligallos 1275, mealla 402, 515, 516, 661, 679, mialla $1237<$ lat. MEDǏALǏA, muller 95, 176, 361, 478, 652, 691, tallar 1896, viella 102, Cantaviella 1, 8, 17, 36, 56,61 . No obstante, hay castellanización en ajos 746, 781, agos 740, 1016, concejo 1339, 1341, concego 1340, 1343, 1347, 1348, 1767, miaga 809, 876, miaja 933, 934, 935, 936, 939, 1225, muger 631, 662, 785, 887, 914, 1748, viego 2010, viegos 937, 956.

3.7. Situación semejante se observa para -CT-, dado que persiste el resultado típicamente aragonés -it-, -t-: dito 1, 7, 8, 10, 15, 22 (cat. dit 486, 1375), dita 212, 283, 289, 1657, ditos 116, 265, 297, 298, 394, 1423, antedito 1956, anteditos 1657, sobre-

Esta tendencia está corroborada por la toponimia pirenaica (Vázquez 2011c: 153-154).

10 No obstante, esta palabra se documenta en algún texto altoaragonés del siglo XIII (Lagüéns 1992: 86). 
dito 204, 205, 206, 298, 392, 393, sobredita 129, 393, 395, 496, 613, 616, sobreditos 10, 734, 1284, 1440, 1664, sobreditas 1664, 1779, feyta 124, 200, 1365, 1625, 1671, 1854 (cat. feta 737), huytanta 199, 1438, 1439, 2123, 2168, peyta 138, 142, 145, 204, 261, 264, profeyta 48. No obstante, se detecta ya la presión castellana en drecho 557, dicho 41, 42, 46, 47, 48, 53, dicha 51, 71, 1249, 1277, 1277, dichos 29, 30, 35, $121,127,1242$, sobredicho $27,1240,1362,1367,1508,1923$, sobredicha 127,128 , 131, sobredichos 1363, 1809, 2111, sobredichas 1375, fecho 17, 34, 62, 63, 66, 69, fecha 25, 27, 48, 242, fechos 1936, fechas 18, 137, pecha 19, 32, 122, 133, pechas 793, 803, 827, lliuras pechantes 940, pechar 499, ocho 248, 249, 254, 264, 288, 293, dizeocho 141, 224, 279, 618, 747, 776, ochocientos 474, 554.

3.8. Los grupos fónicos iniciales PL-, CL-, se conservan en pluviés 149, plegamos 670 , plegar 209, 1223, 1224, 1279, 1709, plegaron 689, 718, 1380, plegasse 728, plegava 36, 155, 1591, 1685, 1686, 1687, plegavan 1262, 1702, 1903, plegó 351, 1706, 2088, plegasen 842, 1387, pleguasse 708, pleguava 843, plegado 570, 1288, 1289, plegada 51, plegados 81 (y el derivado aplegó 863, aplegasen 1002), plegamiento 705, plegueros 1945, clamar 1469, 1470, 1474, clama 230, clamado 200, 213, 294, clamados 130, 331, 391, 625, 732, 864.

3.9. Aparece la consonante palatal /j/ <-DY- en puya 8, 39, 43, 1438, 1666, 1673 , puye 2160 , puia 1743 , puyan $8,42,1668,1923,1945,2120$, puyavan 1659 , puyava 2211 , puyaron 2083, puyó 164, 436, 2086, puyesa 1924, 1925. Por contra, en pugar 980 y pujado 2185 se refleja seguramente la articulación fricativa prepalatal sonora catalana [3]. Por otra parte, la palatalización de las secuencias latinas $\mathrm{G}^{\mathrm{e}, \mathrm{i}} \mathrm{y} \mathrm{I}^{\mathrm{v}}$ se atestigua en janero $802,944,1440,1655$, genero 1299,2174 , jenero 1305 , aunque ya se anota castellanización en ermandat 755, 2067. También se registra el desarrollo del sonido [J] a partir de los grupos latinos - $\mathrm{SC}^{\mathrm{e}, \mathrm{i}}$ - y -PS- en peix 745, caxonero 18,112 , cayxonero $^{11}$ 1680, 1709 (vid. Fort 1986: 32).

3.10. Otros fenómenos testimoniados son: uso de [j] como recurso deshiatizador en seyer 129, 242, 297, 343, 395, 465, veyer 667, 863, 1960, trayer 1690, 1694, 2134; evolución del grupo latino -TR- > - r-, -ir- en confraria 112, 121, 203, 250, 296, 320, cofraria 1227, 1663, 1690, 1755, 2065, cofrarias 1813, 2051, 2092 frayre 78, 235, 244, 245, 257, 352 (cf. cat. frare 595, 59, 1457, 1475), frayres 1798, peyron 152; prótesis de consonante labial en vuevos 52.

3.11. Además de algunas soluciones catalanas, mencionadas en los comentarios precedentes, se atestiguan otras a lo largo del libro de cuentas:

a) Pérdida de - $n$ final: admució 978, Anthó 1293, arendació 431, Bordó 781, clavahó 348, 349, compensació 1426, florí d'oro 929, messió 1005, moravadí 851, notació 2097, procesió 1753 , processió 781 , relació 1620 , Tronchó $665,1181,1318$, $1326,1357,1370$.

b) Cambio vocálico $a>e$ en sent Jhoan 1560, 1936, como es habitual en la scripta catalana medieval (vid. Veny 2007).

c) Síncopa de -D- intervocálica en preyquó 1250, 1457, 1467, 1472, 1475, preyquar 1798 (cf. preycá 523 en un asiento escrito en catalán).

d) Sonorización de -F- en devesa 1844-1849, devessa $1768<$ lat. DEFĒNSA 'de-

Los dígrafos - $i x-,-y x$ - tal vez reflejan la pronunciación característica del catalán occidental, según la cual se articula el sonido vocálico que acompaña al prepalatal. En la documentación de Teruel del siglo XV estudiada por Terrado (1991: 56-58) se registra - $x$ - sistemáticamente, y el dígrafo no parece ser frecuente en la de otros ámbitos de Aragón; cf. peix en un documento zaragozano de 1500, según Enguita (2000: 277). 
hesa', solución conocida también en occitano y portugués, que convive en el texto turolense con defesa 139, 1765, 1799, 1805, 1823, deffesa 893, común al castellano, catalán y aragonés (cf. DECat III, 43; Fort 1986: 15).

e) En el caso de jutglares 146, 150, 380 (del lat. JOCŬLARIS), resultado de la castellanización morfológica del catalán medieval jutglar, aparece una consonante dental que tal vez refleja la articulación geminada del grupo romance secundario -C'L- (Badia Margarit 1984: 232), frente las formas regulares juglar 1553, 1639, juglares 653, 920, 1477. Dicha pronunciación explicaría también las variantes jutlares 1390, 1414 y gutlars 1330, en las que se ha eliminado la consonante velar gráfica por considerarse innecesaria.

\section{Rasgos gramaticales}

4.1. Se registra la forma femenina del adjetivo común, solución aragonesa compartida con el catalán (cf. CORDE): expensa comuna de la baylia 303.

4.2. En la formación del plural, encontramos esporádicamente la adición directa del morfema $-s$ en palabras cuyo singular acaba en consonante o semivocal: pensions 1360 , procesions 1531 , mogons 1768 , nichils $1359,1769,2126$, reys 1476 , conselers 1360, gutlars 1330. Ciertamente se trata de una solución aragonesa muy bien documentada en textos septentrionales (cf. Enguita/Lagüéns 2012: 101; Vázquez 2011a: 19), ${ }^{12}$ pero no en manuscritos meridionales, ${ }^{13}$ por lo que bien podemos concluir que se trata de un rasgo catalán en el libro de cuentas de Mirambel. En cambio, el plural dinés 392, 473, 475, 493, 969, 1021 es la solución generalizada en aragonés, de igual modo que en catalán. Por otra parte, ha de considerarse catalana la terminación -es para voces cuyo singular acaba en - $a$, como es el caso de dies 1525, 1582, banastes 99, onzes 361 .

4.3. Aunque la documentación conocida confirma que el aragonés utilizó el artículo lo (vid. Enguita 2008: 253; Vázquez 2011a: 20; Enguita/Lagüéns 2012: 101), también es cierto que fue prácticamente desconocido en los documentos meridionales (cf. Terrado 1991: 94). En el libro de Mirambel encontramos cinco ejemplos: lo segundo día 515, lo pagament de la coronación 730, lo procés de la Cuba 733, lo vicari de la Cuba 776, lo blat que es en casa 1211. Por el contexto en el que se hallan, es posible que, en este caso, se trate de la forma propia del catalán medieval, actualmente restringida al ámbito de su dialecto occidental. También es catalana la contracción dels 473, 488.

Además, se emplea el artículo personal femenino en alla Vicenta 1407, la Mingueta 50, y ante el apellido feminizado la Foresa 1934, posible reflejo del uso coloquial del artículo ante antropónimos (cf. Terrado 1991: 197), tal vez influido por el catalán en este caso.

4.4. En cuanto a los demostrativos, debemos comentar la presencia de est 201, forma apocopada documentada en algún texto medieval aragonés (Alvar 2000: 178) y viva en el catalán del Bajo Cinca (cf. Galan/Moret 1995: 50; Moret 1996: 42; Moret/Sasot 1996: 37). Asimismo, se registra un ejemplo del demostrativo neutro

12 También la toponimia pirenaica conserva este comportamiento (vid. Vázquez 2011b: 155-176). No obstante, ya en textos del siglo XIV se advierte el retroceso de este rasgo en favor del alomorfo -es (cf. Nagore 2003: 230).

13 Tanto Terrado (1991: 88) como Enguita/Lagüéns (2012: 104), no aluden a este rasgo en los manuscritos turoleses, de lo que se deduce que no se atestigua en ellos. 
catalán alló 'aquello': alló que era tuvido a adar por la ányma de su suegra 2174. También es catalán el posesivo sua 'suya': vista la sua anyada 254, general en la scripta catalana hasta el siglo XVII (Martí Mestre 1994: 150).

4.5. En una ocasión aparece el pronombre de tercera persona li como complemento indirecto: por un hombre que li aiudava 420. Aunque es cierto que se atestigua en aragonés medieval (cf. Alvar 1953: 212), en el libro de Mirambel habrá que considerarlo catalanismo, sobre todo por encontrarse la anotación original insertada entre otras escritas en catalán, en las cuales se emplea dicha forma de dativo.

4.6. Se localizan algunos ejemplos de los derivados de IBI $>h i, y$ e INDE $>$ ende, $n e$, con valor locativo o de complemento preposicional, rasgo que comparten el aragonés y catalán: et vinieron hi de los de Cantaviella 1255, quando nos presentó la monitoria Manuel Naves fiz citar a los quey devían 1320, los quales hi deví él pues no le quieren pagar 1379, e ne pagó el dito Domingo Dolç a la dita huest e cavalgada DLXIII s. 209, e sen fazen abatir XXXX liuras 370, aprés se acordó ne enviásemos media rova más 1316, pagué por la expensa fecha en los erbatges e ne toquó a Mirambell cient dos $s$. 2181, mas sende abatió vinthiseys sueldos dos dineros por cierta expensa de Jayme Miralles 10, costó una copia quende fizieron fazer II s. 65, lende metieron LXXX liuras 370, e quiso sende fazer de los mil s. que teníamos primero 385, ultra los que sende vinieron 616, fuele ende fecha gracia al dito Camariellas de cient s. 1243, los quales no sende ha avido sino LXXV s. 1274, e fue ende tomado en conto XXVI S. 1316, e no ende tomaron en conto sino XXX s. diez dineros 1379, le fazen abatir $\checkmark$ ll. de Jayme Camanyes que ende teníe más II s. 1438, el lugar lende faze gracia 1551, quando sende fue Pere Castelló 1816. También se registran ejemplos de la variante aragonesa yde con idéntico sentido locativo (Terrado, 1991: 212-213): fue yde dos días a piet 1593, e meterlas yde a el y al moço por pacto 1691, fizo un auto públiquo que noyde eran los comisarios 1818, fueron cargados al dito Jhoan Adam et noyde tenía data 2164.

4.7. Se utiliza el relativo qui, tanto referido a cosas como a personas, como sucede en aragonés y catalán: pora ligar el árbol del peyrón qui va a Cantaviella 152 , los guardias qui son Pere Adam e Johan Besaldú 188, pagué a los vedaleros qui son Johan Ortiç e Miguel Miralles 189, adobó la puerta de la villa qui se clama el portal de Peralta 230, por al comissario del príncep qui era Jayme Mofort 285, sobre los bienes de Miguel Torán, qui es heredero del dito Miguel Torán 372.

4.8. En una ocasión se recoge con valor adjetivo el distributivo cada seguido del artículo un: en cadaun anyo 191. También se hallan otras formas claramente tomadas del catalán: en cascún anyo 192, faze de pensión quascún anyo 193, quiscún anyo 194, 195, 199, 250. Asimismo, es catalán el indefinido altre: hun cánter Plana e altre del Forcallo 916. En cambio, ambas lenguas comparten el empleo del pronombre res: fue a Tronchón por tornar la respuesta de la demanda del comendador que no deliberava de darle res 936.

4.9. Entre las formas adverbiales de carácter locativo, se testimonia de suso 25 , 298, 387, 388, 389, desuso 2100 y su variante catalana de sus 1504, desús 1362, $1363,1450,1733,1862,1920$. Sentido contrario tiene deyús 1746, con variante di$y u$ s en el adjetivo conseleros diyuscriptos 1299; la variante con $d$-protética se anota en la forma prepositiva dius obliguación de todos mis bienes 943 . Por otra parte, se registran las formas aragonesas d'alto 465, 466, 493, 771, 772, 777, de alto 937, entaquá 877 y antaquá 802, 804, 810; sin embargo, son catalanas las soluciones dalt 495, daval 1665 y adepart 11, 1792, a de part 1538 . 
4.10. Entre los adverbios y locuciones adverbiales con sentido temporal, son propiamente aragonesas agora 138, 982, toda hora 943, toda ora 1536 (cf. cat. antiguo tothora), del mismo modo que las expresiones el anyo más cerqua pasado 1427, 1574, 1680, 1957, 2130 (cf. cat. proppassat), dia de Nadal primero vinent 468 (cf. cat. primer vinent). Son compartidos por el aragonés y el catalán aprés $34,76,77$, 102, en aprés 123 y encara 1414, 2174.

Con sentido modal tenemos ensemble 112, 121, 1238, a piet 227, 271, 278, 706, 756, 976, a pyet 1687, asín ${ }^{14}$ 122, 124, 138, 201, 204, 206 (usado en la locución conjuntiva asín que 125, 369) y la locución explicativa ço es 499, 521, 781, 827, 876, 1001. En cambio, proceden del catalán a cavall 976, en continent 1240 y nou 136 (por reducción de la locución de nou 'nuevamente').

4.11. La expresión de un límite temporal o local se realiza mediante la preposición fins, usada también en catalán: dada por medio anyo fins Sant Johan 1415. No obstante, fins a y fins en predominan en todo el texto: fins a la present jornada 1299, fins ha hoy 1299, fue con ellos fins al Tronchó 1405, fins en la present jornada 396, 493, 496, 629, 924, 931, fins en la present anyada 937. También se localiza entro a con el mismo valor: entro a la present jornada 298, 1364, entro al present día de oy 464, 466, entro a los contos de octubre 1852, fue con el virrey entro al Forcallo 1933. Sin embargo, junto a las formas autóctonas, se registra ya la castellana fasta (cf. Nagore, 2003: 460): fasta el conto clamado conto de octubre 200, fasta el día de sant Johan 260, fasta Castellot 280, fasta oy 294, fasta en la present jornada 489, 876 , fasta hoy 1732, fasta que fiziemos el contracto 385, fasta que fue de día 561 . En un solo caso se documenta esta preposición $\sin f$-inicial: asta él 16.

Para indicar la conformidad o la concordancia con alguien o algo, se utiliza la preposición aragonesa segunt en todo el texto: segunt que stá en huna cédula adepart 11, segunt consta de la part de suso 25, 201, 205, 297, segunt consta por el libro 123, segunt consta de su rebuda 204, segunt constan por un libro 213, etc. En un solo caso se anota la solución catalana segons, con variante seguns en otra entrada del libro: segons consta de la part dalt 495, seguns una cedulla 1309.

También son catalanas las preposiciones ab y per: que no bastó ab scot a la despesa 224, ab la baylía 1328, per lliuras de Gabriel Miralles 622, per lo procés de la Cuba 733, Pere Soler per moble 776.

4.12. En lo que atañe a la morfología verbal, son varios los aspectos observados propios del aragonés:

a) Apócope de - e en ciertas formas verbales, rasgo que no pervive actualmente: aví fecho 1358, aví a cobrar 1359, aví plegado 1361, aví pagado 1383, fiz 174, 348, $350,703,713,1320$, viniés 165 , ayudás 182,184 , tomás $275,569,1415$, levás 1412 , aduxés 1311, fues 360, 942, 1327, hoviés $667 . .^{15}$

b) Formación del participio de pasado sobre el tema de perfecto, fenómeno muy frecuente en el aragonés de todas las épocas: tuvido 1415, 1733, 2174, tuvidos 1706. También son aragoneses los participios fuertes compreso ‘incluido’2116, compresos 1538, meso 1351, mesas 1355.

c) Vacilación entre las terminaciones -ía, -ie, en la tercera persona del singular del imperfecto de indicativo y del condicional, si bien predominan con diferencia

14 No es forma específica del aragonés, pero está especialmente presente en la documentación aragonesa, como en la obra de Fernández de Heredia (cf. Lagüéns 2009: 41).

15 Para el imprefecto de sunjuntivo, vid. Alvar (1953: 222) o Nagore (2003: 381-382). 
las primeras: avie $8,21,23,131,132,1281$, devie 1301, 1479, perdie 1517, querie 1260 , tenie $1243,1438,2107,2122$, venie 1473 , darie 1536, pagarie 1703 . Señala Terrado (1991: 123) que en los documentos turolenses por él estudiados, esta vacilación solamente se atestigua durante la primera mitad del siglo $\mathrm{xv}$, hecho que parece indicar que las formas en -ie fueron abandonadas desde entonces. No ocurre así en el manuscrito de Mirambel, redactado en el último cuarto del mismo siglo, de lo que se colige que dicha vacilación persistía entonces, tal vez favorecida por la influencia del valenciano. También se advierte esta variación en las terminaciones -ían, -íen de la tercera persona del plural del imperfecto de indicativo y del condicional: ${ }^{16}$ avien 62 , $66,72,76,1261,1285$, devien 1287, dezien 2054, fazien 1580, 1812, querien 102, sien 1536, teníen 1310, tornarien 2067.

d) Uso de las variantes fónicas sía 202, 206, 323, 324, 390, síen 1536 para el presente de subjuntivo del verbo ser.

e) Pérdida de la vocal protónica en el futuro recebrán 403 y en el condicional perdría 1297. Asimismo, se atestigua en una ocasión el condicional poría 168, con caída de la consonante dental, frecuente en textos aragoneses medievales (cf. Vázquez 2011a: 49; CORDE). Todas estas soluciones de futuro responden a fonética catalana.

f) Analogía ejercida por los radicales del tema de presente sobre los perfectos fuertes latinos y tiempos afines: damos 1412, 1414, 1416, daron 42, 43, 154, 356, 1306, 1393, dásemos 174, 275, 1404, 1409, 1413, dase 1238, dasse 712, dasen 1299, avió 175, 1732, avese 1333, fazié 101, 1259, 1326, 2120, trayó 553, 837, trahyó 727 , trayessen 700 .

g) El perfecto de los verbos en -er, -ir tiene los morfos diptongados propios de los perfectos débiles, coincidiendo con los recogidos en el Alto Aragón (Buesa/Castañer 1994: 81): fazié 101, 1259, 1326, 2120, die 453, 457, 459, 463, 687, 898, huvié 165, scrivié 775, vinié 344, recebié 470, 480, 481, 926, 931, 1303, stuvié 342, 345, avió 175,1732 , huvió $179,288,733$, aclariemos 252, aclareciemos 867 , diemos 1397, fiziemos 243, 272, 357, 385, 668, 1257, recibiemos 151 , reconociemos 153 , stuviemos 1314, 1322, 1588, tuviemos 1406 , vidieron ${ }^{17} 1240,1285,1567,2110$. Hay que mencionar también la solución fizién 331 para la tercera persona del plural del pretérito perfecto simple de fer, cuya desinencia debe explicarse por regularización analógica con las restantes formas del paradigma (cf. Buesa/Castañer 1994: 94). También por analogía con otros verbos se habrá desarrollado stuvién 334 (cf. Buesa/ Castañer 1994: 90).

h) Las formas aragonesas fue (yo) 334, 342, 1582, 1583, 1584, 1586, fuemos 274, $343,725,1256,1257,1313$, del perfecto simple de $i r$, todavía son registradas en el Alto Aragón por el ALEANR (Buesa/Castañer 1994: 105).

i) Si bien en todo el texto predomina fazer y su paradigma, todavía se atestiguan fer 166, 219, 346, 688, 706, 1311, 1768 y sus formas conjugadas: fan 984, fará 1415, faría 1351, farían 247, feyta 124, 200, 1365, 1625, 1671, 1854.

j) Desde una perspectiva sintáctica, cabe señalar el empleo del verbo ser con valor locativo (cf. Terrado 1991: 201): hun mas de la Vinolla que es en la Cuba 1769, fueron en la taxación de las pechas 793, fueron en la dita taxación 794 y la fórmula fueron presentes 112, 121, 203, 296, 391, 396. Hay que remarcar igualmente el uso de ser en lugar de haber para indicar la anterioridad en los tiempos compuestos de la voz pasiva

Cf. Terrado (1991: 124), quien registra un solo ejemplo en la documentación turolense que analiza.

Con conservación de la -D- intervocàlica etimológica (Buesa/Castañer 1994: 96). 
y, en tales casos, la aparición del participio del verbo estar (vid. Terrado 1991: 200): era stada fecha 242, era estado tachado 1238, eran estados tornados 1291.

Del uso del futuro de indicativo en el núcleo verbal de las oraciones subordinadas que expresan contingencia, solamente hemos hallado un caso: e es tuvido al frau que, si fará o dará, fuelle dada por medio anyo fins sant Johan 1415.

k) Como perífrasis de obligación, aparece generalmente la construcción haver $+a+$ infinitivo, muy poco utilizada ya en castellano a finales del siglo XV, contrariamente a lo que sucede en aragonés y catalán, y conservada hoy en el aragonés pirenaico (Terrado 1991: 207): avie a dar 23, 1229, 1231, 1285, 1445, 1670, avie a estar 21, avie a fazer 8, havie a dar 1929, havie ha recebir 2116, avie a cobrar 1240 , avie a plegar 1242, avie a tornar 1295, avie a comprar 1983, avie ha tornar 1569, avie ha recebir 1443, avie ha hir 1870, avien a cargar 1285, aveys ha cobrar 125, ha a tornar 8, ha a cobrar 1368, han a pagar 1355 . No obstante, y contrariamente a lo testimoniado por Terrado (1991: 207), en diversas ocasiones ha desaparecido la preposición: ha haver 83, 88, 1273, 1485, 1486, 1494, an haver 84, 93, 1487, 1495, 1604, han haver 1603, 1897, 2039, 2040, havian fazer 708, havian yr 754, havía yr 758, 761, ha dar 952, ha pagar 1356, a pagar 1357, 1358, avia aver 1393, ha perder 1402, avien asignar 1526, an aver 1630, avie aver 1798, avie haver 1881.

La obligación también se expresa en algunas ocasiones mediante la combinación tener + de + infinitivo: tiene de haver 83, 92, 1270, 1602, 1785, 1829, tiene de dar 2192, 2196, 2197, con pérdida de la preposición en tiene haver 1269, 1484, 2025, 2097 (cf. fos tengut de dar 401 en asiento escrito en catalán).

4.13. Pertenecen al catalán algunas soluciones verbales atestiguadas a lo largo del manuscrito, como los participios compensat 1050 y feta 737 , o las formas del pretérito perfecto simple aní 1360, aná 789, doní 683, 837, 838, 859, doná 480, loguí 269, prediquá 1795 , vené 769 , anaren 521 , masaren 790 . También parece haber adoptado la desinencia catalana - $i$ la forma stuví 1331, 1401, 1411, 1582, 1583, que convive en el texto con stuve 1586, 1587. Otra solución esporádica catalana es el condicional auría, hallado en dos ocasiones: si auría algún furto 697, si auría algún frayre 715.

\section{Numerales}

Dedicamos un apartado específico a los numerales, puesto que, dentro del nivel morfológico, resultan especialmente interesantes las formas que presentan los cardinales, frecuentes y abundantes en este manuscrito dada su tipología.

Predominan las soluciones aragonesas, siendo interesantes siet 168, 173, 174, 256, 490, 495, con apócope; пиеu 145, 152, 171, 228, 253, 293, con apócope y vocalización de la consonante latina en posición final; dotze 63, 128, 195, 403, 1361, 1562, tretze 28, 1682, 2060, setze 162, 254, 713, 935, 1539, 1680, setse 1630, seze 878, coincidentes con las catalanas; dizesiet 396, 1252, dizenueu 100, 217, 263, con reducción del diptongo originario; vint 8, 48, 79, 261, 267, 337, trenta 189, 380, 492, 623, quaranta 757, 1293, 1296, cinquanta 117, 136, 186, 190, 193, 194, sixanta 192, 210, 380, 475, setanta 798, 1239, 1850, huytanta/huitanta 23, 199, 1438, 2123 y novanta ${ }^{18} 1923$, también presentes en catalán; dozientos 468, 477, 492, 952,

\footnotetext{
18 Se trata de una solución dialectal en catalán, utilizada en el subdialecto ribagorçà (DCVB).
} 
952 y trecientos/trezientos 125, 187, 298, 384, que conservan la forma etimológica, frente a los compuestos quatrozientos 20, 619, 1301, cincientos 10, 53, 128, 324, 618, seyscientos 1653, 2104, 2109 (con reducción consonántica en seycientos 299), setecientos/setezientos 1282, 1292, 1563, 1780, ochocientos 474, 554, 1283. Son castellanos los numerales ocho 248, 249, 254, 264, 288, 293, dizeocho 141, 224, $279,618,747,776$ (dieciocho 306) y ochocientos/hochocientos 474, 554, 613, 1283 , 1300, 1733 (este último aparece siempre, a pesar de utilizarse huytanta sistemáticamente); de manera esporádica se usan quarenta 250 y novecientos 19, 297, 627. También se emplean formas catalanas, todas ellas en convivencia con las respectivas aragonesas: quatre 472, 1021, cinch 303, 331, 473, 498, sis 246, 493, 716, set 467, nou 490, 492, 674, 799, 802, vint e set 1406, vint e nou 630, 782, vint hi nou 1844, sixanta quatre 475, vuytanta 470, 733, vuytanta dos 614, noranta 1565,1670 , noranta tres 799 , noranta quatre 472 , cent cinquanta sis 482 , tres cents noranta tres 1440, mil quatrecens quaranta set 1021, dos mil cincents dos 493, tres mil sexanta sis 630, tres mil cent 392.

Esta coexistencia de variantes para un mismo numeral, ha ocasionado la creación de compuestos mixtos, de modo que se combinan dos o incluso tres constituyentes de distinta procedencia, hecho que se constata igualmente en otros textos turolenses del siglo XV (cf. Terrado 1991: 100-102) e incluso en algunos ribagorzanos del siglo XVI (Giralt 2013: 82-83):

a) Aragonés y castellano: vint e ocho 492, vint hi ocho 1666, vinthiocho 21, trenta ocho 386, 486, 1245, 1678, quaranta nueve 1923, sixanta ocho 1230 , setanta ocho 926, cient cinquanta ocho 1564, trezientos quaranta ocho 1938, 1944, quatrozientos trenta ocho 1776, cincientos dizeocho 324, ochocientos vint hi cinquo 2171, ochocientos trenta 1921, ochocientos trenta tres 2170, ochocientos quaranta hun 2109, ochocientos quaranta quatro 1654, ochocientos quaranta siet 1283, 1286, ochocientos huytanta 1922, 1926, mil seiscientos cinquanta ocho 1375, 1424, mil ochocientos quaranta tres 876, mill ochocientos sixanta seys 809, mill novecientos sixanta quatro 627, dos mil cincientos dieciocho 306, dos mil ochocientos quaranta 1948, dos mill ochocientos cinquanta ocho 943, 945, 950, dos mil hochocientos sixanta tres 1300, dos mill ochocientos sixanta seys 803, dos mil hochocientos sixanta VIII 1733 , dos mil ochocientos setanta siet 771 , dos mil novecientos cinquanta et un 19, tres mil quatrozientos huytanta ocho 1304, 1363, tres mil novecientos vint e siet 297.

b) Aragonés y catalán: noranta seys $1637,1730,1924$, noranta et seys 1515 , cient vint e sis 302, cient trenta set 950 , cient vuytanta cincho 470, cient vuytanta siet 733 , cient noranta et quatro 1944, dozientos noranta nou 773, trecientos noranta set 125 , quatrozientos noranta quatro 1935 , cincientos cinquanta nou 618 , cincientos sixanta quatre 2158, noucientos vint 1286, 1293, noucientos trenta hun 1920, noucientos sixanta 1929, 1935, noucientos noranta nueu 2166, mil cient noranta tres 202, mille dozientos noranta 934, mil seyscientos noranta tres 1732, 1733, mil noucientos vuytanta cinquo 1020, dos mil cient noranta tres 206, dos mil noucientos dos 1567 , dos mil noucientos quaranta hun 1784, dos mil noucientos cinquanta hun 394, dos mil noucientos noranta tres 123.

c) Catalán y castellano: ochocientos vuitanta dos 613, ochocientos noranta ocho $1421,1425$.

d) Aragonés, castellano y catalán: cincientos noranta ocho 2114, ochocientos noranta nueu 2159. 
Por otra parte, hay que citar el empleo del adjetivo múltiplo doblén, registrado también en el siglo XIV en documentación valenciana $(C I C A)$, variante de los antiguos doblè i doblenc del catalán (DCVB, s.v.): dizeocho sueldos del doblén dinero 776 , le tomaron en conto el doblén diner de las liuras 1240, por los doblén dineros 1554, se pierden en el doblén dinero de las lituras 1840.

\section{Léxico}

En el libro de cuentas de Mirambel se manifiesta igualmente la convivencia de lenguas en el vocabulario, porque subsisten palabras que corresponden al acervo léxico del aragonés (algunas de ellas compartidas por el catalán), junto a otras, en menor número, que solo pertenecen al del catalán. ${ }^{19}$ Los campos semánticos a los que pertenecen los términos están condicionados por la tipología textual en la que se encuadra este manuscrito, y es por ello que buena parte del léxico que comentaremos a continuación está conformado por tecnicismos jurídicos y económicos; además, en la relación de gastos que se desarrolla en el texto hay numerosos términos relativos a aspectos más concretos, como los salarios, las dietas, las obras, las fiestas y procesiones, los productos y materias primas, etc. que el concejo sufragó a lo largo de los catorce ejercicios contables que abarcan las anotaciones.

6.1. Se enmarcan en el campo de la terminología económica voces como las siguientes: abatimiento 800 [abatimientos 1433, 1678, 1778, 1779, 1923] 'descuento, deducción de una cantidad' (cf. cat. abatiment), abatir 10, 53, 125, 127 [abatidas 10, 1009, abatida 206, 1432, 2172, 2199, abatidos 127, 393, 611, 799, 800, 876, abatido 1385,2126 , abatió 10, abaten 1422, abatieron 1287] 'descontar, restar una cantidad de otra' (cf. cat. abatre), bisconto 1008 'trabacuenta, error o equivocación en una cuenta' (cf. cat. bescompte), bistraer ${ }^{20}$ [bistrayó 16, 59, 1290, 1276, 1552, 1761, bistrahió $207,208,300,301,302,328$, vistrayó 1662 , vistrayeron 1419 , bistraydo $1370,1936]$ 'anticipar, dar dinero de antemano o tomarlo' (cf. cat. bestreure), bestre$t^{21} 1749$ 'anticipo de un pago', conto ${ }^{22}$ 8, 9, 26, 28 [contos 11, 130] 'cuenta, cálculo' (cf. cat. compte), deudo ${ }^{23} 951$ 'deuda' (cf. cat. deute), disconto 126 'descuento', doblero $^{24} 1014$ 'que vale el doble de una unidad dada' (cf. cat. dobler), emparamiento 1323, 1518 [emparamientos 208] 'embargo' (cf. cat. emparament), emparar [emparó 234] 'embargar' (vid. Lagüéns 1992: 116-117), empera ${ }^{25} 693$ 'embargo' (cf. cat. empara), esmerçar [esmerçados 492] 'comprar', guanyo ${ }^{26} 154$ 'ganancia' (cf. cat. guany), logar [logo 1294, 1585, 1896, logaron 1477, loguí 269, loguada 799]

19 Resulta realmente complejo determinar si en algunos casos estamos ante préstamos de una lengua en otra. Ello es debido, tal y como afirma Lagüéns (2009: 29), a la conformidad léxica evidente entre una y otra área lingüística y a la existencia de determinadas coincidencias fónicas y morfológicas favorecedoras de la integración de los préstamos propiamente dichos en el sistema receptor.

20 Cf. Lagüéns (1992: 69), con amplia información relativa al uso del vocablo en aragonés.

21 También existe la variante bistreta (Enguita/Arnal 1995: 172; DCVB, s.v.).

22 Voz habitual en documentación medieval aragonesa (vid. Terrado 1991: 252; Vázquez 2011a: 35); nótese la ausencia de diptongación.

Cf. Lagüéns (1992: 112).

24 No tiene aquí el sentido de 'panecillo pequeño en forma de rosca', propio de Aragón (DLE, s.v.).

25 También se registra en documentos jaqueses del siglo XIII (Alvar 2000: 207).

26 Así aparece en otros documentos zaragozanos y turolenses del siglo XV (CORDE; Terrado 1991: 273). 
'alquilar' (cf. cat. llogar 2135), loguero ${ }^{27}$ 471, 1447, 1568, 1785 [logero 1303, 1406, lloguero 947] 'alquiler' (cf. cat. lloguer), penioras ${ }^{28} 1320$ 'prenda como garantía del cumplimiento de una deuda o de un pago' (vid. Terrado, 1991: 292), penyorar 1287 'empeñar, embargar', perdua 135, 782, 1394, 2045, 2047, 2160 'pérdida', peyta 138, 142, 204, 261, 376, 1293 'tributo o contribución', renda 722, 1351 [rendas 240, 1351, 2177] 'renta', tachar 29 32, 1747 [tachamos 364, 365, tacharon 29, 289, 800, 1234, 1461, 1462, tachados 1235, 1547, 1729, 1740, tachado 239, 386, 1317, 1539] 'tasar', venda 7, 1289, 2156 'venta' (cf. asiento contable $\mathrm{n}^{\mathrm{O}} 765$ redactado en catalán).

Son formas catalanas carnage 30893 'impuesto sobre las carnes destinadas a la alimentación', cens ${ }^{31}$ 57, 89, 473, 639, 818, 1340 'censo, tipo de tributo', minvar [minvaron 158, 288, 293] 'mermar, menguar', minvas 158 'mermas', pagament ${ }^{32}$ 197, 1401 [paguament 730] 'pago', peyter ${ }^{33} 1293$ 'quien está obligado a pagar la pecha', quitament 277, 495, 2190 'pago', rebuda ${ }^{34}$ 202, 303, 1787, 1955, 2120, 2160 [rebudas 1022, 1375] 'entrada en caja'.

Incluimos en este apartado algunos nombres de monedas: liura 2, 361, 394, 941, 1288 [liuras 120, 126, lliuras 400, 620, 622, 675, 738, 776, lliura 620, 776, 782, 803, 882, 915] 'libra', mealla 402, 515, 516, 661, 679 [mialla 1237, 1925] 'meaja, tipo de moneda antigua de poco valor', puyesa 1924, 1925 'moneda de muy poco valor' (cf. cat. pugesa ${ }^{35}$ ). Es vocablo catalán sou 473 [sous 392, 475, 482, 493, 630, 733] 'sueldo, moneda antigua'.

6.2. Como hemos señalado, también la terminología jurídica (entendida esta en un sentido amplio) mantiene numerosas palabras de origen aragonés: affronto 839 'afrenta, vergüenza y deshonor' (cf. cat. afront), ajust 73, 90, 91 'reunión de gente para tratar algo', calonias $^{36} 1415,1917$ 'pena pecuniaria que se imponía por ciertos delitos o faltas', carta de comanda 803, 809, 1300 'carta de depósito' (cf. Lagüéns 1992: 81-82), castigamiento 185 'castigo' (cf. cat. castigament), condapnados 1418 'condenados', crida 1714 [cridas 898] 'pregón; convocatoria', cridar 855, 911, 919 'convocar; pregonar', dicisoria ${ }^{37} 1327$ 'decisión', esguart ${ }^{38} 1301$ 'atención, consideración a una cosa', fitar 1256, 1632, 1765, 1799 'amojonar', fitas 2184 'mojón', frau 1415 'fraude' (cf. Lagüéns 1992: 138-139; Vázquez 2011a: 42), imposar 32,

Cf. Lagüéns (1992: 174), quien confirma su amplia localización en las fuentes navarro-aragonesas.

28 No obstante, en el manuscrito se emplea regularmente la voz castellano-aragonesa pendra 1591 [pendras 1521, 1526, 1618], variante metatizada de prenda (vid. Lagüéns 1992: 212).

29 Solución aragonesa, conocida en catalán medieval, variante de la castellana tasar. En el texto de Mirambel se registra también la forma culta taxar 941 [taxado 965, taxados 977, 1006] (cf. Lagüéns 1992: 257).

30 Variante gráfica del carnatge. En aragonés se utilizó carneraje (Fort 1994: 206).

31 Solución catalana, también presente en la documentación aragonesa, que ofrece dos resultados para el plural en el libro de cuentas de Mirambel: censos 153, censes 611 (cf. Fort 1994: 206. Alvar 2000; 205).

32 Sobre este término se ha creado el plural anómalo pagamentes 1669.

33 Esta voz catalana en el libro de Mirambel solamente aparece en una ocasión, frente a la castellana pechero 1294, $1333,1386,1949$.

34 Convive en el manuscrito con el cultismo recepta 25, 124, 202, 299, 300, 301 [receptas 18, 137].

35 También se hallan algunos ejemplos en documentación castellana del siglo XIII (CORDE).

36 Cf. Lagüéns (1992: 71-72), quien ofrece amplia información respecto al uso del término en aragonés.

37 Sustantivación del adjetivo decisorio 'decisivo' en su forma de femenino, de la que se halla un testimonio en un texto aragonés de $1480(C O R D E)$; tal vez pueda explicarse a partir de la reducción del sintagma letra decisoria, tal y como se registra en documentación catalana de comienzos del siglo XV (CICA).

38 Sobre el empleo de este significante en documentación antigua aragonesa, vid. Lagüéns (2010: 45). Añadiremos que también se registra en otros textos turolenses del siglo XV (Terrado 1991: 260). 
145, 264, 319 [imposaron 142, 261, 1575, imposada 19, 394, 627, 1300, 1443, 1567, imposadas 803, impossada 138, 204] 'imponer', ligallo 1261, 1380, 1419, 1460 [ligallos 1275] 'legajo'. (cf. cat. lligall), liuramientos 879 'entrega' (cf. cat. lliurament), liurar 917 [liuradas 1319, liuraría 698] 'librar, entregar' (cf. Lagüéns 1992: 173), mandatge 1929 'mandato', misagería 880, 935, 1277 'mensaje, comunicación transmitida por mensajero' (vid. Vázquez, 2011a: 46), plegar $^{40} 209$, 1223, 1224 , 1279, 1709 [plegava 36, 155, 1591, 1685, 1686, 1687, plegavan 1262, 1702, 1903, pleguava 843, plegó 351, 1706, 2088, plegamos 670, plegaron 689, 718, 1380, plegasse 728 , pleguasse 708, plegasen 842,1387 , plegado 570, 1288, 1289, plegada 51, plegados 81] 'reunir', plegamiento 705 'reunión' (cf. cat. plegament), presón 160, 282, 283, 1540 'prisión' (cf. cat. presó), protest 706 'acció de protestar' (cf. protestación 942), requesta 289 'requerimiento', robamiento 2185 'robo' (cf. cat. robament), stablimiento ${ }^{41} 1299,1427$ [stablimientos 203] 'estatuto, reglamento' (cf. cat. establiment).

Son catalanes los términos deliurament 763, 764 'entrega, acto de poner en poder de otro' (variante antigua del cat. deslliurament), eratada 2102 'heredada', guardatge 1271 'guardia, custodia' (y su variante guardiatge 1227, 1228 por analogía con guardia), presoners 731 'prisioneros', sagrament 7255 [sagraments 685] 'juramento', vedament 1590 'prohibición, impedimento'.

6.3. Diversas son las voces aragoneses que aluden a dignidades, cargos u oficios: almudaçaf ${ }^{43}$ 112, 121, 203, 296, 1022, 1241 [almudaçaff 396] 'almotacén, oficial municipal encargado de la vigilancia de las pesas y medidas', baylía 1, 10, 34, 48, 49, 51 'bailía, cargo y jurisdicción del baile' (cf. cat. batlla), baylio ${ }^{44}$ 36, 48, 103 'baile, funcionario que ejerce autoridad por delegación' (cf. cat. batlliu), bolseria 808, 1018, 1634 'tesorería', bolsero 141, 301, 733, 944, 1220, 1300 'tesorero' (cf. cat. bosser), caridaderos ${ }^{45}$ 907, 913, 1393, 2182 'caritatero, limosnero', castellán 336, 503, 850, 851, 862, 1687 'gobernador de un castillo' (cf. cat. castellá 443, 505), caxonero 18, 112 [cayxonero 1680, 1709] 'cajero', comptadores 206 'contables, encargados de llevar la contabilidad' (cf. cat. comptadors), correu 50, 56, 73, 90 'correo', dezeneros 209 'caporal de un grupo de diez hombres' (cf. cat. desener), frayre 78, 235, 244, 245, 257, 352 [frayres 1798] 'fraile', fustero 1556 'carpintero' (cf. cat. fuster), laurador 1099 'labrador', menobra 1005 'manobre, peón de albañil' (cf. cat.

39 Posible formación aragonesa derivada del sustantivo mando. No se encuentra paralelo ni en catalán ni en castellano.

40 También se halla la variante aplegó 863, aplegasen 1002 (aplegá 579, apleguá 576, 580, aplegaren 602, apleguaren 584, en asientos escritos en catalán); cf. cast. allegar.

41 Sobre la forma catalana se ha creado la variante stablimento 1775.

42 Voz catalana presente en textos antiguos aragoneses (vid. Fort 1986: 33; Lagüéns 1992: 242; Lagüéns 2010: 36), en los que también se atestiguan las variantes sagramento, sagramient.

43 Forma aragonesa del término de origen árabe, también conocida en catalán antiguo (DECat $\mathrm{V}$, 812b), en la que se manifiesta la sonorización de la consonante dental interior -cf. almudaçafes en las Ordinaciones de Barbastro (Vázquez 2011a: 30)-, a diferencia de almutaçaf (cf. cat. ant. mustaçaf), atestiguada en documentación turolense del siglo XV (Terrado 1991: 226).

44 Derivado de baile, tal vez de una forma latina hispánica BAJǓLIVǏUM, que en catalán resultó batlliu, forma esta documentada ya en el siglo XII y de la que existen abuntandes testimonios en textos roselloneses de los siglos XIII y XIV (DECat I, 728a). En el DLE (s.v.) se recoge con el significado de 'caballero profeso de la Orden de San Juan, que tenía bailiaje', con un sentido mucho más restringido que el que posee baile en aragonés (vid. Lagüéns 1992: 66-67)

45 Frente a las soluciones semicultas cast. caritatero y cat. caritater, encontramos en el libro de cuentas esta variante aragonesa más popular, formada sobre el sustantivo caridad. 
manobra), misatgero 1870 [misatgeros 171, 1526, misageros 521, 1380, 1387, 1695] 'mensajero' (cf. cat. missatger), perpostre 46250 'mayordomo de una hermandad o cofradía' (cf. cast. preboste y cat. prebost), príncep 61, 68, 69, 70, 255, 256 'príncipe', quitador 131 'funcionario encargado de las quitaciones de los censales', rendero 1430 [renderos 1496, 1615] 'rentero, quien paga o cobra una renta' (cf. cat. render), sobrecollidor 2018 'recaudador', sobrejuntero 677 [sobregunteros 1360, 1379] 'funcionario, de nombramiento real, que presidía la junta instituida para la persecución de los malhechores y ejecución de las sentencias del rey y del justicia' (cf. cat. sobrejunter), tachadores $^{47} 1765,1766$ 'tasadores', vedalero 1824 [vedallero 1337, 1415, vedaleros 85, 189, 310, 450, 636, 814] 'guarda de un lugar' (cf. cat. vedaler).

Aparecen, asimismo, voces catalanas, algunas en convivencia con sus respectivas aragonesas: mustaçaf ${ }^{48}$ 1442, 1740 [mustaçaff 391, 626, 802, 1299, 1377, mostaçaff 1299, almustaçaff 944], bisbe 49 1 'obispo', bogi 780, 799 'verdugo', bosería 733, carder 678 'cardero, quien hace o vende cardas', frare 1457, 1475 (también en los asientos contables $n^{0} 595,596$, escritos en catalán), fuster 1942, jutge ${ }^{50} 943$ 'juez', mege 1112 'médico' (cf. Terrado 1991: 281; Fort 1994: 220), pedrapiquero ${ }^{51} 620$ 'picapedrero', vedaler 986.

6.4. Productos de diversa índole y materias primas constituyen, asimismo, un referente importante en lo que respecta al léxico aragonés: alméndolas ${ }^{52} 518,1309$ 'almendras', çafrán 5, 7, 54, 147, 210, 361 [çaffrán 557, 679, 720, 782, 1217, 1301, zaffrán 475] 'azafrán' (cf. cat. safrà), çaffranar 778 'azafranal' (cf. cat. safranar), cevada ${ }^{53} 45,74,1597$ [civada ${ }^{54} 2214$ ] 'avena', cuyrambre 55704 'corambre, conjunto de cueros o pellejos, curtidos o sin curtir, de algunos animales', fresadura 1325 'conjunto de galones o tiras estrechas de tejido fuerte, a modo de cinta, que guarnecen los vestidos y otras cosas' (vid. Lagüéns 2010: 73), frasquas 11, 51, 72, 81 [frascas 1681, 1693] 'bagatelas, cosas de poco valor', frasqueras 28 'conjunto de frascas o bagatelas', fusta 1759, 1760 'madera', gingebre 857 'jengibre’ (vid. Sesma/Líbano

46 Variante metatizada de la voz aragonesa prepostre < lat. PRAEPǑŠTTU, atestiguada en documentación medieval jaquesa (Alvar 2000: 250).

47 Solución aragonesa, variante de la catalana taxador y la castellana tasador. En el manuscrito de Mirambel aparece igualmente la forma culta taxadores 786.

48 Esta variante está presente en la Ordinación dada a la ciudad de Zaragoza por Fernando II de Antequera de 1414 (CORDE).

49 Vocablo catalán usado en ocasiones en documentos medievales aragoneses, en lugar del autóctono bispe (vid. Fort 1986: 21-22; Fort 1992: 156; Lagüéns 2010: 42).

50 Como indica Lagüéns (1992: 161), esta voz está muy presente en la documentación medieval aragonesa y cabe ponerla en relación con las variantes existentes en catalán, occitano y francés, si bien matiza que hay estudiosos que la han considerado peculiar del aragonés antiguo (como Gunnar Tilander), mientras que otros (como Ángeles Líbano) opinan que se trata de un calco en los documentos navarro-aragoneses. Por su parte, señala Vázquez (2011a: 10) que debe ser un préstamo del catalán, a pesar de estar registrado en los escritos de los notarios de los valles pirenaicos más occidentales. Cf. también Nagore (2003: 195).

51 Tal vez adaptación del catalán pedrapiquer, muy utilizado en tortosino y valenciano (DCVB, s.v.).

52 Arcaísmo del aragonés (cf. Sesma/Líbano 1982: 79; Terrado 1991: 226), con una consonante lateral a imitación de las palabras de origen arábigo en al-.

53 Consideramos que este es el significado de la palabra en el manuscrito, habida cuenta que aparece el término ordio con el sentido de 'cebada' (cf., no obstante, Sesma/Líbano 1982: 147; Fort 1986: 24-25; Fort 1992: 59; Enguita/Arnal 1995: 176 y 177; Vázquez 2011a: 33). Por lo tanto, se trata de un uso semántico característico del aragonés y del catalán.

54 También se anota este significante en el asiento contable $n^{\circ} 545$, redactado en catalán.

55 Variante aragonesa del castellano corambre y del catalán cuiram, registrada en otros documentos aragoneses del siglo XV (cf. Sesma/Líbano 1982: 163; Giralt 2013: 92). 
1982: 219), mostacia 514, 744 'mostaza' (vid. Sesma/Líbano 1982: 263), noguera 1371 'nogal', olio 262, 514, 651, 740, 1016, 1256 'aceite' (cf. cat. oli), ordio 288, 1436, 1998 'cebada' (cf. cat. ordi), pansas 567 'pasas', paper 4, 8, 55, 170, 251, 265, pebre 361, 745, 857, 912 (cf. Fort 1986: 31-32), prunas 742 'ciruelas', roures 274, 713, 977 'roble', tozineta 1762 'panceta'.

Son catalanas las palabras siguientes: amellas 567, 577 'almendras', blat 1211 'trigo' (predomina trigo en todo el libro de cuentas), cabrons 1393 'machos cabríos', çafrà 1667, 1673 [çaffrà 857], cansalada 1873, 1875 'carne curada con sal para su conservación, especialmente tocino' (frente al sintagma aragonés carne salada 2015), coure 1859, 1904, 1905, 1923, 1960, 1961 'cobre', formage ${ }^{56} 650$ 'queso', pollastre 1597 [pollastres 1454, 1990, 2068] 'pollo'.

Hay vocablos que hacen referencia a medidas de longitud y de capacidad: alna 1728 'medida de longitud que servía para medir la ropa y debía equivaler a un metro aprox.' (cf. cast. ana), barciellas 117 'barchilla, medida de capacidad de áridos', caffiç ${ }^{57}$ 22, 39, 1403, 2174 [caffiz 974, 1001, cafiç 21, 39, 45, 132, 1222, 1882, caffices 132, 482, 492, 613, 970, 1212, cafices 615, 1222, 1289, 1361, 1440, 1510] 'cahíz, medida de capacidad para áridos', quarta 790 'medida de líquidos equivalente a un litro aprox.', quartales 39, 492, 613 'medida de grano que corresponde a la duodécima parte de la cuartera (aprox. 70 litros)'. Formas catalanas son barcella 2172 'barchilla, medida de capacidad de áridos', cánter 399, 590, 599, 916 [cánters 864, 909] 'cántaro, medida de vino equivalente a unas 28 libras' (aunque en el libro predominan cántaro, quántaro)

6.5. Podemos mencionar igualmente algunos objetos y utensilios: bacíos 12, 340, 669, 1352, 1511, 1965, vacíos 1923 'bacía, vasija para contener líquidos u otros usos', clau 852, 1267 'clavo', grillones 1268, 1778 [grilones 1767] 'grilletes' (cf. cat. grilló), mancha 1974 [manchas 1557, 1583, 1594, 1975, 1969, 1988] 'fuelle', quicalera 1697 [quicaleras 1691, 1697, 1698] 'quicial, quicio de las puertas y ventanas', rodol ${ }^{58} 1529$ 'rodete', taula 1900, 1994 'tabla, mesa'. Añadimos bacín de los pobres 153, locución que, a pesar de estar formada por el sustantivo bacín 'vasija pequeña para diversos usos', parece referirse más bien, según el contexto en el que se usa, a una institución encargada de recoger dinero para un fin benéfico, tal y como se constata en catalán antiguo (DCVB, s.v. bací; Fort 1994: 99).

Son voces catalanas las siguientes: banchs 348 'banco, asiento de madera con respaldo o sin él', cadenage 173 'conjunto de cadenas' (cf. Sesma/Líbano 1982: 126), capel 1687, 1703, 1705, 1797 'sombrero, cubrecabeza' (cf. Sesma/Líbano 1982: 138), clavahó ${ }^{59}$ 348, 349 'clavazón, conjunto de clavos puestos en alguna cosa, o preparados para clavarlos', cuberta 1697 'pieza que cubre algo', fusa ${ }^{60} 1541$,

56 Voz atestiguada en catalán, aragonés medieval y castellano antiguo. En el texto de Mirambel, no obstante, se utiliza sistemáticamente queso $2,184,363,490,514$, por lo que cabe pensar que se emplea aquí por influjo catalán; además, se halla en las entradas escritas en catalán (por ejemplo, en los asientos contables n 411,517 , $526,550,605)$.

57 También aparecen las variantes cafis 226, 246, 254, 266, 325, 327, caffis 680, 707, 1361, 1431, cafises 225, $226,227,228,238$, con una consonante alveolar que bien puede deberse a una confusión del escribano, en parte motivada por la articulación de la palabra en catalán (cf. Fort 1994: 243).

58 Variante del aragonés y catalán redol < lat. ROTǓLU, con mantenimiento de la vocal etimológica.

59 Variante antigua del catalán clavasó, con pérdida de $-s$ - intervocálica ante vocal acentuada (Badia Margarit 1984: 191). También se registra en algunos libros de collidas aragoneses del siglo XV (Sesma/Líbano 1982: 154).

60 En propiedad, se trata del participio de pasado del verbo catalán fondre 'fundir', que por extensión de su signi- 
2054 [fusas 2089] 'campana', full 1781 'hoja', garbell 1693 'garbillo, especie de harnero o zaranda hecha de esparto a manera de criba' (cf. Sesma/Líbano 1982: 218),

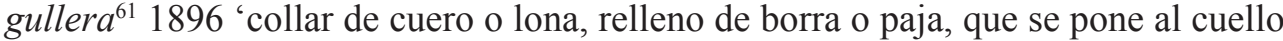
a las caballerías o a los bueyes para que no les haga daño el horcate', landa 1697 'lámina de metal' (anotada también en el asiento contable n 437, escrito en catalán), marquavines ${ }^{62} 855$ 'variedad de clavos', palys ${ }^{63} 2174$ 'palio', panyos ${ }^{64} 855$ 'cerraduras', pean ${ }^{65} 349$ 'pedestal, pie o peana', peças 2143 'piezas', plats 2146 'platos'.

En el ámbito de la construcción, cabe citar: antuxano 1571 'antuzano, espacio situado delante de una casa u otro edificio, o cercano a ellos, y destinado a diversos fines' (cf. cat. antuixà), finiestras 778 'ventanas', forado 'agujero' 854 (cf. cat. forat), lumera 1778 'lomera, caballete de un tejado' (cf. cast. lomera y cat. llomera). Además, se emplea el verbo adobar ${ }^{66}$ 100, 149, 231, 346, 415, 854 [adobaron 366, 1381, adobo 230, 374, 1746, 1767, 2176] 'remendar, reparar' y su derivado adobo 374 'reparación' (cf. cat. adob). Son catalanas las voces finestras 432, rajolla 568 'ladrillo' (cf. Sesma/Líbano 1982: 308; Terrado 1991: 297), suminera 349 'chimenea’ (variante gráfica del catalán dialectal xuminera; cf. xemeneia).

6.6. Debemos incluir, además, otros términos pertenecientes también al léxico común aragonés: aclarir ${ }^{67}$ [aclariemos 252] 'poner en claro una cuestión', atrobar [atrobado 126, 205, 393, 465, 946, 1213] 'hallar, encontrar', aturar 837, 1816 [atura 926] 'detener, parar', conosança ${ }^{68} 1331$ 'conocimiento', cremar [cremaron 1482] 'quemar', esleír [esleydos 802, 1022, 1307] 'elegir' (vid. Terrado 1991: 261; Lagüéns 2009: 34), esvenir ${ }^{69}$ [esvenería 175] 'acaecer, tener lugar' (cf. cat. esdevenir), exir 175 [exidos 1898] 'salir', exida 1821 'salida', faular ${ }^{70} 60,61,275,359,372,431$ [faulasse 902] 'hablar', finar [finado 1678] 'terminar', fosar 1548 'cementerio', janero 802, 944, 1440, 1655 [genero 1299, 2174, jenero 1305] 'enero’ (cf. cat. gener),

ficado habría adoptado el sentido de 'campana', teniendo en cuenta que la fabricación del objeto se lleva a cabo a partir del hierro fundido (cf. $D C V B$, s.v.).

61 Variante de gollera y, a su vez, de collera, por influencia de goll 'papera, bocio' (DECat IV, 558a).

62 Adaptación del cat. marcavins; cf. Sesma/Líbano (1982: 252) y Terrado (1991: 280).

63 Forma de plural del catalán pal·li, que aparece aquí fosilizada con valor de singular. Según Coromines, se trata de un uso coloquial, del que únicamente aporta como ejemplo una cita de una obra de Martín Gadea de principios del siglo XX (DECat VI, 201b-202a). Un ejemplo anterior se halla en el Dictionarium seu Thesaurus Catalano-Latinus Verborun ac Phrasium de Pere Torra de 1640: «Palit o palis de altar. Antipendium» (DCVB, s.v. pal·li; debemos indicar, no obstante, que Alcover y Moll manejaron la edición de 1726). En cualquier caso, el manuscrito de Mirambel nos permite ofrecer un testimonio más antiguo de esta particularidad morfoléxica.

64 Por el contexto en que aparece el término, está claro que se trata de la adaptación del catalán pany, y no tiene aquí el significado de 'trapo', como en otros manuscritos aragoneses de la misma época (cf. Sesma/Líbano, 1982: 278).

65 Préstamo léxico procedente del catalán peany, atestiguado en el área norte de la Comunidad Valenciana (DCVB, s.v.; DECat VI, 503a).

66 Con este sentido, fue verbo especialmente usado en aragonés y catalán (cf. adobar 588, adobaren 590, 598, en asientos contables escritos en catalán). En una sola ocasión aparece con el significado de 'poner o echar en adobo carnes'.

67 Como sinónimo se emplea aclareciemos 867, del castellano aclarecer (cf. Terrado 1991: 223), que convive con la variante latinizada aclarescer 1871, aclarescieron 1873.

68 Variante del término aragonés conoxença (cf. Lagüéns 2010: 44; Vázquez 2011a: 34); cf. cat. coneixença y cast. ant. conocencia.

69 En otros textos turolenses del siglo XV se registra evenir (Terrado 1991: 263).

70 Resulta compleja la interpretación fónica de estos significantes, puesto que, si bien puede suponerse una semivocalización de la consonante bilabial latina, también puede pensarse que su pronunciación era realmente $[\beta]$ (Lagüéns 2010: 48). 
lexar ${ }^{71}$ [lexo 287, 1529, 1541] 'dejar' (cf. cat. lleixar), leyr 697 'leer' (cf. cat. llegir), mancar [manquava 868] 'faltar', Nadal 13, 16, 59, 1329, 1476, 1483 'dia de Navidad', pervenir [pervenieron 503] 'llegar', peyrón ${ }^{72} 152$ 'cruz de término, colocada sobre un pedestal de piedra', porgar 970, 1659, 2002 [porgó 970] 'ahechar', posar ${ }^{73}$ [posa 1, 2, 3, 4, 5, 6, possa 412, 1306, 1686, 1718, possan 1419, poso 152, 403, 726] 'poner, indicar, establecer', proveyr 1530 'proveer' (cf. Vázquez 2011a: 50), puyar ${ }^{74}$ [puya 8, 39, 43, 1438, 1666, 1673, puye 2160 , puia 1743 , puyan $8,42,1668,1923$, 1945,2120 , puyavan 1659 , puyava 2211 , puyaron 2083 , puyó $164,436,2086$ ] 'subir', regismo 569 'reino' (cf. cat. regisme), regonocer 7500 [regonocieron 399] 'reconocer' (cf. cat. ant. regonèixer), romanir [romanieron 800] 'permanecer' (cf. cat. romandre), treballar 1411 [treballa 286] 'trabajar', treballo 720, 1420, 1498, 1514, 1538, 1630 [treballos 1344, 1709] 'trabajo' (cf. cat. treball), trobar [trobo 666, 1358, $1359,1979,2103,2174$, trobaron 126, 1547, trobados 2126] 'encontrar', vegada 383 [veguada 891, vegadas 1297, 1432, 1550, 1592, 1933] 'vez'.

Asimismo, localizamos palabras que pertenencen al léxico común del catalán: adur 167, 869, 1557, 1757, 2003, 2028 [dur 1968] 'llevar, traer', affegir 1312 'añadir', almoyna ${ }^{76}$ 452, 638, 646, 816, 987, 1715 'limosna', caritat 790, 836, 1012 'caridad', carnestoltes 897 'carnaval', clot 1972 'hoyo', creença 'creencia' 697, fereginal 620 'herrenal, terreno en el que se siembra forraje para el ganado', finament 627, 933, 953, 2099, 2111 'final, término', fira 1313, 1327 'feria', graner 657, 659, 1682 'granero', juliol 1377 'julio', parels 975 'par', pelerich ${ }^{77} 1324$ 'picota', pobils 800, 1668, 1923 [castellanizado en pobiles 1778] 'infantes, personas menores de edad', profit 206 'provecho', scriure 969 'escribir', tros 1372 [troç 1888] 'trozo, pedazo', valença 870 'amparo, ayuda, favor'.

\section{Anotaciones escritas en catalán}

Al margen de los elementos característicos del catalán que hemos señalado en los apartados precedentes, completamente integrados en la scripta del libro de cuentas, se halla un total de 130 asientos contables ${ }^{78}$ redactados en dicha lengua. La mayoría

71 Cf. Lagüéns (1992: 170-171), donde se nos ofrece amplia información sobre el uso de esta palabra en documentación aragonesa medieval.

72 Cf. cat. occ. peiró (DECat VI, 367b).

73 Esta voz propia del oriente peninsular (Lagüéns 2010: 53) se ve ya sustituida en algunas anotaciones por el castellano poner (en concreto, en los asientos contables n ${ }^{\circ} 152-386,448-463,2176-2188$ ).

74 Es muy probable que la variante gráfica pugar 980 aparezca por influjo del catalán.

75 También se emplea la solución latinizante castellano-aragonesa reconoscer 1255, 1465, 1509, 1517, [reconoscida 2102, reconoscieron 1240, 1295, 1456, 1627, 1928, 1939] (cf. Lagüéns 1992: 229).

76 En el libro de cuentas de Mirambel convive con almosna 57, 86, 191, 195, 312, 456 [almosnas 2092] 'limosna', voz antigua conocida en castellano, aragonés y catalán (Fort 1994: 151).

77 Voz registrada por Coromines en textos del Maestrazgo, Castellón de la Plana y Matarraña del siglo XVI (DECat VI, 398b), aunque también está presente en otros de origen aragonés anteriores a los mencionados: pellyerich en las Ordinaciones de Barbastro de 1396 y pellerich en la Ordinación de Zaragoza de 1414 (vid. CORDE; Vázquez 2011a: 48).

78 En concreto: 401, 402, 404, 405, 407, 408, 409, 411, 412, 413, 414, 416, 417, 418, 421, 422, 423, 424, 425, 426, $427,428,428,430,433,434,435,437,438,439,440,441,442,443,444,445,446,481,485,497,504,505$, $506,516,517,518,519$, de 522 a 552 (ambos inclusive), 555, 556, 558, 559, 560, 562, 563, 564, 565, 566, de 572 a 610 (ambos inclusive), 759, 765, 791, 861, 2135, 2169. 
de ellos corresponden al período del bolsero Jaime Cubells, quien refleja a lo largo de sus anotaciones y en primera persona un uso continuado de ese idioma, siendo trasladado tal y como aparece en sus albaranes fielmente por el notario Bernat Cristóbal, lo que viene a confirmar, según Navarro Espinach (2008: 23), que el escribano copiaba literalmente los borradores y apuntes que le entregaba cada jurado responsable de las cuentas. En dichas anotaciones se ratifica, una vez más, la consabida homogeneidad de la lengua catalana escrita en época medieval, puesto que su lectura da cuenta de la presencia de pocas particularidades lingüísticas y la mayor parte de ellas muy generalizadas en la scripta catalana medieval, si bien es cierto que emergen algunos rasgos de la oralidad propia del dialecto occidental (Veny 2014: 1).

7.1. En el nivel fónico, se observa cambio de la vocal tónica en sent Martí 529, sent Jordi 600; la combinación latina -ACT- ofrece los resultados - eit- (feyt 580) y -et(fet 582, 584, 608, 2169, 609, 610, feta 584); aparecen derera 404 y tengut 401 con modificación de la vocal átona inicial; se mantiene - e como vocal de apoyo de la consonante vibrante en ferre 437; se registran las formas regonèxer 404, 411, 541, regoneguem 537, regonoximens 531, donde la consonante velar sonoriza regularmente (cf. reconèixer); por influjo de otras voces próximas se produce el cambio $c \rightarrow f$ en proffessió 589, 593 'procesión' (cf. processió, processó); existe prótesis en vuytanta 481, pero no en huyt 485 (como en el valenciano actual); se suprime la vibrante en el grupo final -rs en ballestés 438 (cf. balesters 759), cordés 604, dinés 418, 422, 562, 601 , indicio inequívoco de su desaparición articulatoria; por un cruce con el cuantitativo quant < lat. QUANTUM, el adverbio temporal quant $<$ lat. QUANDO incorpora - $t$ antietimológica (cf. Giralt 2012: 48). Por otra parte, estrictamente dialectal es el cambio de la vocal tónica en ampre 413 'préstamo' (cf. empre), por influjo del verbo amprar, variante occidental de emprar 'prestar' (DCVB, s.v.).

7.2. En el nivel morfológico, cabe resaltar el plural hòmens 417, 530 como descendiente del proparoxítono latino HŎMĬNES, solución medieval que perdura en catalán occidental (Veny 1991: 132-133); el posesivo etimológico sua 2169, general en la lengua antigua hasta el siglo XVII (Martí Mestre 1994: 150); el uso del adverbio pus 2169 con el valor temporal de 'después' (fue visto que Jhoan Adam havie a dar a Francisco Montanyés CCCLXVI S. III segons apar en fi de compte fet per Matheu Çorita, pus dels quals en doná lo dit Francisco Montanyés per la sua resta docents sous); la desinéncia etimológica de $4^{\mathrm{a}}$ persona en anam 597, general en la lengua medieval (Badia Margarit 1984: 127-128) e incluso en documentación leridana del siglo XVI (Farreny 2004: 282); las formas del imperfecto de subjuntivo anassen 440, anasen 607 , vinguessen 404, 444, 578, 583, propias del catalán antiguo (vid. Badia Margarit, 1984: 362-363), todavía existentes en el catalán de la Ribagorza y el balear (Giralt 2012: 146); la $3^{\text {a }}$ persona fonch $576<$ lat. vulg. *FUT del pasado simple del verbo ser, de formación analógica (Pérez Saldanya 1998: 240).

7.3. Por lo que respecta al nivel léxico, hay que mencionar los vocablos siguientes: aleres $^{79} 421$ 'piedra gruessa y plana que se coloca junto a otras sobre una pared, para que el ganado no salte', empleado en el norte de Castellón ( $D C V B$, s.v. alera); aparer [apar 2169] 'aparecer' (cf. DECat VI, 285b); *apilarar ${ }^{80}$ [apilararen 530], que parece significar 'apuntalar con pilares un edificio' (cf. port. apilarar 'adornar

79 No se trata en este caso de la voz altoaragonesa alera o alera foral 'derecho de pasto reconocido legalmente', documentada a mediados del siglo XV, de posible origen protovasco (DECat I, 121b-122a).

80 En catalán se registra con el sentido de 'cubrir el fuego para mantenerlo durante la noche' (DCVB, s.v.). 
o apuntalar con pilares'), no se ha localizado con este valor en ninguna de las obras consultadas; bacis 524 'gamella, artesa que sirve para dar de comer y beber a los animales'; canelles 531, variante antigua de candeles 517 [candelles 518] 'vela', hoy conservada en valenciano (DECat II, 469b); carasqual 541 'carrascal, lugar poblado de carrascas', actualmente utilizado en catalán occidental (DECat IV, 394a); cordés 'corderos', usado en catalán occidental; minguar [minguaren 562] 'menguar', usado hoy en una parte del Maestrat valenciano (DECat V, 597b) y en la Franja de Aragón (cf. Galán/Moret 1995: 92; Moret/Sasot 1996: 74; Giralt 2005); plegador 600 'colector de limosnas y donativos', significado antiguo en catalán (DECat VI, 606b); terraz 791 'jarro de boca ancha' (DCVB, s.v. terràs).

En los asientos contables redactados en catalán también se observa la convivencia de soluciones pertenecientes a distintas lenguas: amellas 577 / alméndolas 518, caritat 591 / caridat 592, carn 537 / carne 516, 531, 541, 550, 584, 592, castellá 522 / castellán 525, compranyero 413, 414, 434, 505 / companyó 504, rebre [rebé 485] / recebir [recebié 481], saffrá 565, 591 / saffrán 546, segons 608, 2169 / segunt 411, 555. Asimismo, resulta interesante el caso del catalán compte 401, 566, 2169, dado que se emplea junto a su variante conte 444, 564 [contes 532], hoy existente en el dialecto occidental, y la forma aragonesa conto 537 [contos 401, 497, 506]; además, aparece conts 404, 434, 446, solución mixta creada a partir de la voz aragonesa, con apócope de - $O$ y creación del plural con el morfo $-s$. También se insertan elementos propios del castellano y del aragonés en la scripta catalana: baylía 409, 434, 505, 522 , 525, 544, 549, cena 516, congrio 577, dineros 519, domingo 861, jantar 516, leyr 414, limpiar 524, morabatín 550, olio 577, pan 518, pendra 582, vino 516.

\section{Consideraciones finales}

En las páginas precedentes ha quedado demostrada la coexistencia de elementos lingüísticos de distinta procedencia en el libro de cuentas del concejo de Mirambel, correspondiente al último cuarto del siglo Xv. Como se ha indicado en la introducción de este trabajo, la scripta que refleja este manuscrito turolense es esencialmente castellana, como ocurre ya desde mediados de esta centuria en todos los textos notariales conocidos procedentes del Valle Medio del Ebro y el Aragón Bajo. Pero, al mismo tiempo, la persistencia de abundantes rasgos propios del romance aragonés viene a corroborar, en palabras de Frago (1991: 125), que «fue extraordinariamente pausada la introducción del castellano en Aragón, también en el seno de los grupos más susceptibles de recibir ese influjo lingüístico y aún entre los individuos que más conscientemente lo buscaron. Esto concedió una gran normalidad al proceso y al mismo tiempo provocó la formación misma del español regional que en este dominio hispánico acabó instalándose, porque no era cuestión de una conquista rápida y sin concesiones, sino del lentísimo acoplamiento del romance invasor con las reminiscencias del que se batía en retirada». Además, este manuscrito turolense ratifica que la castellanización a partir de finales del siglo XV fue más lenta en los textos notariales que en los textos literarios por estar vinculados a la vida cotidiana (Enguita/Arnal 1995: 161).

Junto al componente lingüístico aragonés, este libro de cuentas nos revela la pervivencia en el texto de peculiaridades propias de la lengua catalana, hecho que ge- 
neralmente se manifiesta en la documentación producida en poblaciones aragonesas próximas a otras catalanohablantes (vid. Enguita 2008: 262), e incluso la utilización de dicha lengua en la redacción de algo más de un centenar de anotaciones. Como señala Lagüéns (2010: 34), "la vecindad geográfica entre Aragón y Cataluña, una historia común de ambos territorios unidos durante siglos bajo una misma Corona, los contactos comerciales y un sinfín de relaciones culturales de la más variada índole configuraron un marco particularmente favorecedor del intercambio lingüístico entre los respectivos romances autóctonos". A esa cercanía geográfica con Cataluña a la que se alude en esta cita, podemos añadir la que existe con el área catalanohablante de la Comunidad Valenciana, circunstancia que explica que en el manuscrito de Mirambel se manifieste la convivencia de lenguas de manera tan notoria.

\section{Bibliografía}

Alvar, Manuel (2000): Estudios sobre el dialecto aragonés. II. Zaragoza: Institución "Fernando el Católico".

Alvar, Manuel (1953): El dialecto aragonés. Madrid: Gredos.

Badia Margarit, Antoni M. (1984): Gramàtica històrica catalana. València: Tres i Quatre, $2^{\mathrm{a}}$ ed. en catalán.

Buesa, Tomás / Castañer, Rosa M. a (1994): "El pretérito perfecto simple en las hablas pirenaicas de Aragón y Navarra”. Archivo de Filología Aragonesa 50: 65-132.

$[C I C A]$ : Joan Torruella, Manuel Pérez Saldanya y Josep Martines (dir.), Corpus informatitzat del català antic, Banco de datos [en línea] < www.cica.cat> [consulta: noviembre de 2017].

[CORDE]: Real Academia Española, Corpus diacrónico del Español, Banco de datos (corde) [en línea] <www.rae.es> [consulta: noviembre de 2017].

DCVB: Antoni M. Alcover y Francesc de Borja Moll, Diccionari catatà, valencià, balear $<$ http://dcvb.iecat.net/default.asp/> [consulta: noviembre de 2017].

DECat: Joan Coromines (1980-2001), Diccionari etimolòic i complementari de la llengua catalana. Barcelona: Curial, 10 vols.

DLE: Real Academia Española, Diccionario de la lengua española $<$ http://dle.rae.es/> [consulta: noviembre de 2017].

Enguita, José María (2017): “Confluencias lingüísticas en el Libro de la Bailía de Cantavieja. Aspectos gráficos, fonéticos y morfosintácticos”, en Serres, identitats i paraules, Emili Casanova y Cèsar Salvo (eds.), pp. 381-405. València: Denes.

Enguita, José María (2008): "Manifestaciones romances en los territorios meridionales del Aragón medieval". Aragón en la Edad Media 20: 249-265.

Enguita, José María (2000): "Contacto de lenguas en el Aragón renacentista”. Aragón en la Edad Media 16: 273-288.

Enguita, José María / Arnal, María Luisa (1995): “La castellanización de Aragón a través de los textos de los siglos XV, XVI y XVII". Archivo de Filología Aragonesa 51: 151-195.

Enguita, José María / Lagüéns, Vicente (2012): “Oralidad y escritura en la documentación aragonesa medieval", en Oralidad y escritura en la Edad Media hispánica, Juan Pedro Sánchez Méndez (ed.), pp. 87-126. Valencia: Université de Neuchâtel-Tirant Humanidades.

Farreny, Dolors (2004): La llengua dels processos de crims a la Lleida del segle XVI. Barcelona: Institut d'Estudis Catalans. 
Fort, María Rosa (1994): Léxico romance en documentos medievales aragoneses (siglos XI y XII). Zaragoza: Gobierno de Aragón.

Fort, María Rosa (1986): Relación del léxico catalán con el aragonés en documentación primitiva aragonesa. Zaragoza: Diputación General de Aragón.

Frago, Juan Antonio (1991): "Conflicto de normas lingüísticas en el proceso castellanizador de Aragón”, en Actas del I Curso de Geografía Lingüística de Aragón, Tomás Buesa y José María Enguita (eds.), pp. 105-126. Zaragoza: Institución "Fernando el Católico".

Galan, Josep / Moret, Hèctor (1995): Estudi descriptiu de la llengua de Fraga. Fraga: Institut d'Estudis del Baix Cinca.

Giralt, Javier (2013): "Empremtes diatòpiques en textos notarials del segle XVI de Roda d'Isàvena escrits en castellà". Alazet. Revista de Filología 25: 77-96.

Giralt, Javier (2012): La llengua catalana en documentació notarial del segle XVI d'Albelda (Osca). Albelda: Ajuntament d'Albelda.

Giralt, Javier (2005): Lèxic de la Llitera. Lleida: Editorial Milenio.

Lagüéns, Vicente (2010): “Contactos lingüísticos y transmisión textual: a propósito del léxico de las Coronaciones glosado por Jerónimo de Blancas (II)". Archivo de Filología Aragonesa 66: 33-96.

Lagüéns, Vicente (2009): “Contactos lingüísticos y transmisión textual: a propósito del léxico de las Coronaciones glosado por Jerónimo de Blancas (I)". Archivo de Filología Aragonesa 65: 13-52.

Lagüéns, Vicente (1992): Léxico jurídico en documentos notariales aragoneses de la Edad Media (siglos XIV y XV). Zaragoza: Gobierno de Aragón.

Martí Mestre, Joaquim (1994): El "Libre de Antiquitats" de la Seu de València, vol. II. València-Barcelona: Institut Interuniversitari de Filologia Valenciana-Publicacions de l'Abadia de Montserrat.

Moret, Hèctor (1996): Sobre la llengua de Mequinensa. Calaceit: Institut d'Estudis del Baix Cinca.

Moret, Hèctor / Sasot, Màrio (1996): Aproximació descriptiva a la llengua de Saidí. Calaceit: Institut d'Estudis del Baix Cinca.

Nagore, Francho (2003): El aragonés del siglo XIV, según el texto de la Crónica de San Juan de la Peña. Huesca: Instituto de Estudios Altoaragoneses.

Navarro Espiach, Germán (2008): Cuentas del concejo de Mirambel (1472-1489). Zaragoza: Departamento de Historia Medieval, Ciencias y Técnicas Historiográficas y Estudios Árabes e Islámicos-Instituto de Estudios Turolenses.

Pérez Saldanya, Manuel (1998): Del llatí al català. Morfosintaxi verbal històrica. València: Universitat de València.

Sesma, Ángel / Líbano, Ángeles (1982): Léxico del comercio medieval en Aragón (siglo XIV). Zaragoza: Institución "Fernando el Católico".

Terrado, Javier (1991): La lengua de Teruel a fines de la Edad Media. Teruel: Instituto de Estudios Turolenses-Diputación de Teruel.

Vázquez, Jesús (2011a): Ordinaciones y paramientos de la ciudad de Barbastro publicados por D. Mariano de Pano. Aspectos lingüísticos. Barbastro: Ayuntamiento de Barbastro.

Vázquez, Jesús (2011b): Sobre fonética histórica del aragonés. Huesca: Publicazions d'o Consello d'a Fabla Aragonesa-Instituto de Estudios Altoaragoneses.

Vázquez, Jesús (2011c): “Aspectos fonéticos, morfonológicos y léxicos del aragonés antiguo desvelados por los topónimos”. Archivo de Filología Aragonesa 67: 143-172.

Veny, Joan (2014): “Cronología de los cambios en catalán de Mallorca según la scripta ma- 
llorquina". eHumanista/IVITRA 6: 1-11 <http://www.ehumanista.ucsb. edu/eHumanista\%20IVITRA/index.shtml>.

Veny, Joan (2007): "San(t) Antoni / Sen(t) Antoni”. Estudis de Llengua i Literatura Catalanes. LV. Homenatge a Joseph Gulsoy. 3. Barcelona: Publicacions de l'Abadia de Montserrat, 215-239.

Veny, Joan (1991): Els parlars catalans. Palma de Mallorca: Moll, 9ª ed. 